\title{
ASPECTOS DE LA ACTIVIDAD INFORMANTE EN LA ADMINISTRACION LOCAL. EN TORNO A UNA NUEVA REGULACION
}

352: 35.077 .7

por

\author{
Alberto Vera Fernández-Sanz \\ Secretario de $1 .^{*}$ categoría de Administración local
}

SUMARIO: I. EL ACTUAL MOMENTO NORMATIVO EN LA ADMINISTRACION LOCAL.-II. LA ACTIVIDAD INFORMANTE EN LA LEGISLACION DE REGIMEN LOCAL.-III. LOS INFORMES DE LOS SECRETARIOS E INTERVENTORES SEGUN EL REAL DECRETO-LEY 3/81, DE 16 DE ENERO. ¿SUBSISTE LA ADVERTENCIA DE ILEGALIDAD?-IV. TRATAMIENTO JURIDICO DE LOS INFORMES EN LA NUEVA NORMATIVA.-V. CODA OBLIGADA: DEL LABERINTO LEGISLATIVO AL GALIMATIAS LOGICO.

I. EL ACTUAL MOMENTO NORMATIVO EN LA ADMINISTRACION LOCAL

La transición política y administrativa de un anterior sistema a un régimen constitucional está produciendo, como es lógico, unos continuos cambios legislativos a los que no es ajena, por supuesto, la Administración local. Sin embargo, y como destacaba el profesor 
GARCf́A DE ENTERRÍA en septiembre de 1979, el necesario procedimiento de reforma del Régimen local se ha quedado a medio camino (1). Aún hoy, dos años más tarde y pese al señalamiento de plazos establecido por el Gobierno, la tan deseada Ley de la Administración local no es más que un Proyecto aprobado por el Ejecutivo sobre el cual el órgano legislativo no ha iniciado su discusión. En el año de la Constitución se pudo afirmar con toda razón por Alejandro Nieto (2) que las Corporaciones locales vivían en un estado de anomia, no tanto por la inexistencia normativa, sino por la confusión y contradicción existente entre Leyes y Reglamentos aplicables al Régimen local, lo que suponía su difícil, cuando no imposible, cumplimiento, y sobre todo por la negativa de los Ayuntamientos a cumplirlas, en unos casos por falta de fuerza política, $y$ en otros por considerarlas obsoletas respecto de la realidad política y social del momento. Si esto es cierto hoy, se puede todavía decir que la situación no ha cambiado tan sensiblemente como para considerar superadas las palabras de NiETo. Ante la circunstancia de unos Ayuntamientos y Diputaciones elegidos democráticamente y el retraso considerable de la nueva Ley de Régimen local, el Gobierno ha optado por lo que un tratadista denominó, respecto de las aguas públicas (regidas en gran parte por la Ley de 1879), como la "solución ortopédica», es decir, proveer de parches y apósitos para que la esfera local pueda cuando menos andar renqueando sin el apoyo de unas disposiciones, ya viejas, que la inmovilizan. Fruto de ello ha sido la proliferación de normás del más diverso rango a la vista de las cuales se llena de razón la afirmación de GARCÍA DE ENTERRÍA en su obra anteriormente citada: la dificultad con que se encuentra el jurista práctico (aquel al que según el maestro Federico de CASTRo sólo le preocupaba la aplicación del Derecho positivo, es decir, "el Derecho que está en vigor en un pueblo determinado") para precisar cuáles son las normas vigentes.

Entre estas normas de carácter inmediato se encuentran el Real Decreto-ley 3/81, de 16 de enero, y el Real Decreto de 5 de junio, también de 1981, que aprueban y desarrollan, respectivamente, debidas medidas de régimen jurídico de las Corporaciones locales, entre las cuales reciben regulación determinados aspectos de la función informante que corresponde a los funcionarios de los Cuer-

(1) Legislación de Régimen local, ed. B.O.E., Madrid, 1979, pág. 7.

(2) «De la República a la democracia: la Administración española del franquismo», en Revista Española de Derecho Administrativo, núm. 18, Civitas, pág. 361. 
pos Nacionales. De ello me voy a ocupar seguidamente exponiendo, en primer lugar, el desarrollo de esa actividad según el Reglamento de Organización, Funcionamiento y Régimen jurídico de las Corporaciones locales en conexión con el Reglamento de Funcionarios, para analizar posteriormente la incidencia en estos temas de la reciente normativa.

\section{LA ACTIVIDAD INFORMANTE EN LA LEGISLACION DE REGIMEN LOCAL}

Se ha definido el informe, a efectos jurídico-administrativos, como «el acto administrativo consistente en una declaración de juicio emitida por un órgano distinto de aquel a quien corresponda iniciar, instruir o resolver el procedimiento y que sirva para aportar nuevos datos al expediente o comprobar los ya existentes en el mismo (3).

El Reglamento de Organización, Funcionamiento y Régimen jurídico trata de los informes en sus artículos 285 y siguientes. De su examen surgen una diversidad de tipos que si bien responden a una técnica bastante elaborada, lo cierto es que encubre auténticos sinónimos, por lo que su relevancia se puede considerar más aparente que real.

En un intento de estructuración, se pueden dividir los informes atendiendo a un criterio material, según el citado Reglamento, de la siguiente forma:

\section{1) Informes administrativos.}

Su emisión corresponde al Jefe de la Dependencia, a quien compete tramitar el expediente.

Su calificación como administrativos, según se expresa en el artículo 285, apartado 2, del Reglamento de Organización, Funcionamiento y Régimen jurídico, sin duda para diferenciarles de los jurídicos y técnicos, es un tanto artificiosa y hay que entenderla con suma reserva. En primer lugar, por razón de quien emanan, los

(3) Blanco DE Tella y GonzÁlez NaVARRo: Organización y procedimientos administrativos, Madrid, Montecorvo, 1975, pág. 300.

Esta parte ha sido objeto de más amplio desarrollo en mi tesis para Diploma en Administración local, presentada en el I.E.A.L. bajo el título: Análisis de los procedimientos de aprobación de planes y proyectos. 
funcionarios Jefes de Dependencias, los cuales, sin duda, pueden también emitir informes de carácter jurídico si ostentan el título de Letrado. En segundo lugar, por el propio objeto del informe, que, según el artículo 285 del Reglamento de Organización, Funcionamiento y Régimen jurídico, no sólo versará sobre los antecedentes de hecho, sino que también se extenderá a las disposiciones legales o reglamentarias en las que funde su criterio, lo que implica una inevitable valoración jurídica.

Estos informes pueden, a su vez, subdividirse en:

A) Informes normales o de impulso (art. 285 ROF).

B) Informes propuestas de resolución (art. $288 \mathrm{ROF}$ ).

Los primeros son aquellos que tienden meramente a la aportación de elementos de juicio como base para la adopción de una resolución. Los segundos, los que además fijan los términos de la resolución a adoptar, como consecuencia de los antecedentes y elementos de juicio que se hayan expuesto, y que contendrán los siguientes extremos: enumeración clara y sucinta de los hechos, disposiciones legales aplicables y alegación razonada de la doctrina y pronunciamientos que ha de contener la parte dispositiva.

$\mathrm{El}$ informe propuesta es un informe final, lo que supone, entre otras cosas, que en el mismo se hará la debida referencia a otros informes provenientes de diferentes servicios que puedan haberse producido a lo largo del procedimiento.

2) Informes jurídicos.

Los informes «en Derecho", como suele decirse en lenguaje usual, pueden proceder:

A) De los funcionarios con título de Letrado (arts. 285 y 289 Reglamento de Organización, Funcionamiento y Régimen jurídico).

B) Del Secretario como asesor de la Corporación y de su Presidencia. Dentro de este supuesto se pueden dar los siguientes:

a) Informes advertencias de manifiesta ilegalidad (art. 143, 1, Reglamento de Funcionarios) (4).

b) Informes referentes a asuntos que lo requieran durante las sesiones (art. 143, 2. RF).

(4) Sobre la vigencia de esta figura me ocuparé más adelante. 
c) Dictámenes cuando lo acuerde la Corporación o lo ordene la Presidencia (art. 143, 3, RF, y art. 286 ROF) (5).

d) Dictámenes en asuntos de importancia, de calificado interés o que por su índole lo precisen (art. 286, 1, ROF, y 143, 3, RF).

e). Informes o notas razonadas, en su caso, de conformidad o disconformidad a informes emitidos por otros funcionarios.

f) Informes previos a los expedientes de suspensión de acuerdos (art. 143 RF) (6).

C) De asesores jurídicos funcionarios.

Cuando las Corporaciones cuenten con asesores jurídicos que sean funcionarios, corresponderá a éstos emitir los dictámenes en Derecho, a petición de la Corporación o del Presidente.

D) Informes de Letrados no funcionarios.

Esta posibilidad se prevé en el ya citado artículo 286,1 , del Reglamento de Organización, Funcionamiento y Régimen jurídico, dejando a salvo las facultades que en este aspecto corresponden al Secretario y mediante solicitud del Presidente de la Corporación.

Como se habrá podido observar, la normativa de Régimen local recoge la diferenciación entre «informe» y "dictamen», según el funcionario del que procedan unos $u$ otros o la índole de los asuntos sobre los que versen aquéllos.

Gramaticalmente, ambos términos son sinónimos (7). Sin embargo, parte de la doctrina más representativa se muestra partidaria de una sutil diferenciación. GARRIDo FaLla critica la utilización indirecta del vocablo «informe» para designar tanto «la actuación de los organismos formalmente consultivos, de tipo tradicional, como de los órganos de asesoramiento e incluso de los pareceres emitidos por los funcionarios a los que está atribuida en general, facultades simplemente instructivas en el procedimiento administrativo" (8), debiendo, a su juicio, reservarse esta denominación para las primeras.

(5) Este tipo de informes ha sido modificado, modificación que será tratada en otro lugar de este trabajo.

(6) La vigencia de este precepto se analizará infra.

(7) Vid. Diccionario de la Lengua Española, Real Academia Española, 19 edición, Madrid, 1970: «Informe: acción y efecto de informar o dictaminar... Dictaminar un cuerpo consultivo, un funcionario o cualquier persona perita en asunto de su respectiva competencia».

(8) Vid. "Informes y dictámenes en el procedimiento administrativo», en Libro homenaje al Profesor López Rod6, tomo I, ed. Universidad de Santiago de Compostela, 1972, pág. 495. 
García-Trevijano mantiene que el dictamen es algo más que un informe o una opinión y que «debe enfocar los temas desde ángulos no estrictamente jurídicos (como las Abogacías del Estado), sino jurídico-administrativos» (9).

Desde otro punto de vista, González Navarro (10) se pronuncia por una opinión contraria y superadora, no otorgando base alguna sustancial a esta diferenciación, carente, a su juicio, de auténtica relevancia.

3) Informes técnicos.

Su emisión corresponde a los funcionarios competentes, según su titulación o profesión. Su variedad comprende los posibles siguientes casos a título meramente enunciativo:

A) De Ciencias de la Administración:

a) Económicos, financieros (v.gr., sobre costos, rentabilidad de un proyecto, perspectivas, etc.).

b) Técnico-organizativos (referentes al vasto campo de la organización racional y métodos).

c) Sociológicos.

B) Técnicos propiamente dichos, referidos a los aspectos de ejecución material, construcción, adecuación a normas o aspectos técnicos, etc. (de arquitectura, ingeniería, etc.).

Obviamente, los proyectos redactados por los propios servicios municipales es ilógico que sean objeto de informe, lo que debe reservarse al caso de aquellos confeccionados por técnicos ajenos a la Corporación. El ejemplo típico es el referente a Planes y proyectos de urbanización de promoción privada.

La intervención de la Comisión informativa.

Aparte de los informes procedentes de los distintos funcionarios o técnicos, el procedimiento municipal prevé la intervención del nivel corporativo a través del trámite de consulta.

Según el artículo 124 del Reglamento de Organización, Funcionamiento y Régimen jurídico:

«Las Comisiones deberán ser consultadas en todos los asuntos que correspondan a la competencia del Ayuntamien-

(9) Tratado de Derecho administrativo, cit., vol. II, pág. 670 .

(10) Ob. cit., pág. 301. 
to Pleno, salvo cuando hayan de adoptarse acuerdos declarados urgentes".

El Reglamento de Organización, Funcionamiento y Régimen jurídico emplea el término "consulta», lo que, como anteriormente hemos expuesto al tratar de los informes o dictámenes, plantea la cuestión de si esta modalidad difiere sustancialmente de los ya expuestos.

GaRrido Falla (11) estima que el vocablo consulta equivale a un informe de garantía formal o informe consultivo, que, a su juicio, son aquellos que se producen sobre la documentación ya aportada al expediente, que se supone ya instruido.

Para GonzÁlez NAvarRo (12), la consulta contempla el lado activo o petición de la relación de informe.

En principio, parece aceptable la denominación de consulta, de acuerdo con la tesis de GARRIDO, pues en el procedimiento municipal, las Comisiones informativas deben pronunciarse una vez se han producido todos los informes técnicos, administrativos o jurídicos, y antes de entrar en la fase resolutoria.

A mayor abundamiento, el artículo 128 del Reglamento de Organización, Funcionamiento y Régimen jurídico prevé que:

«El dictamen de la Comisión podrá limitarse a mostrar su conformidad con el de Secretaría, y en caso contrario habrá de razonar el disentimiento».

Es decir, que presupone un previo informe de Secretaría, el cual, a su vez, y en su caso, se emite sobre otros de los diversos servicios (13).

El principal problema que plantea el informe, consulta o dictamen de las Comisiones informativas es el de su obligatoriedad.

El citado artículo 124 se muestra contundente en su expresión gramatical al imponer el deber de consulta, la cual, cuando se trata de acuerdos o resoluciones de la competencia de la Comisión Permanente o del Alcalde, será potestativa (art. $125 \mathrm{ROF}$ ).

La jurisprudencia no ha sido, sin embargo, tan tajante en la interpretación de estos preceptos, en cuanto a la posible omisión del

(11) Informes, cit., pág. 508.

(12) Ob. cit., pág. 302 .

(13) El Reglamento de Organización, Funcionamiento y Régimen jurídico no es un modelo de precisión terminológica en este aspecto. El artículo 124 habla de «consulta». Los dos siguientes, de «informes o asesoramientos»; el 128, en concreto, de dictámenes, cuando realmente se está refiriendo a la misma figura. 
trámite informativo de consulta. La sentencia del Tribunal Supremo de 25 de noviembre de 1962, declara que sólo cabe anulación de los actos o acuerdos municipales por razones de trámite, cuando los defectos alegados sean esenciales o produzcan indefensión, llegando a la conclusión de que:

«... tenemos que dejar sentado que no aparece tal, dado que la omisión del informe o propuesta de la Comisión informativa y del asesor jurídico alegada, con infracción de los artículos 122 y 124 del Reglamento, no tiene el alcance que le da el demandante...; asimismo no es defecto de trámite el que no haya oído previamente a la Comisión informativa, porque bien no puede existir reglamentariamente en la Corporación demandada, ya que el artículo 90 del Reglamento de Organización, Funcionamiento y Régimen jurídico prescribe que para la preparación y estudio de los asuntos podrán dividirse los Ayuntamientos en Comisiones informativas..., cuya redacción gramatical demuestra que es una facultad o posibilidad legal que se concede a las Corporaciones locales, mas no una obligación legal. El establecimiento de tales Comisiones, por otro lado, se deja a la discrecionalidad de la propia Corporación en base a sus necesidades".

Los informes de otras autoridades y organismos de la Administración.

El artículo 75 de la Ley de Procedimiento Administrativo admite la posibilidad de cumplimiento de trámites por otras autoridades y organismos de la Administración distintos del que instruye el expediente.

Entre dichos trámites se encuentra la emisión de informes, en virtud de un precepto legal o reglamentario que así lo exija.

Este supuesto es harto frecuente en el procedimiento local debido a las competencias compartidas o paralelas que en una misma materia pueden ostentar tanto los Entes locales, como otros órganos de la Administración central o institucional.

El cumplimiento de este trámite debe acomodarse a lo dispuesto en la Ley de Procedimiento Administrativo como norma supletoria del Régimen local, esto es: petición del informe por el órgano local, concretando los extremos acerca de los que se solicita el dictamen 
y citando el precepto que lo exija (art. $84 \mathrm{LPA}$ ); remisión de los antecedentes necesarios y consignación en la comunicación del plazo legal establecido para la emisión del informe (art. 75 LPA), con la advertencia de que de no recibirse en el plazo señalado proseguirán las actuaciones (art. 86 LPA) (14).

\section{LOS INFORMES DE LOS SECRETARIOS E INTERVENTO- RES SEGUN EL REAL DECRETO-LEY 3/81, DE 16 DE ENE- RO. ¿SUBSISTE LA ADVERTENCIA DE ILEGALIDAD? (15)}

El Real Decreto-ley 3/81, de 16 de enero, regula algunos de los informes que, en ejercicio de su función, han de emitir determinados funcionarios, cuales son los Secretarios e Interventores de Administración local en el marco de sus respectivas competencias.

Dichos informes, que se configuran como necesarios, se refieren:

a) A la adopción de acuerdos para los que se exige un quórum especial.

b) A los casos en que lo ordene el Presidente de la Corporación o lo solicite un tercio, al menos, de sus miembros, siempre con antelación suficiente a la sesión en que hubiese de adoptarse el acuerdo que lo motiva. El primer caso supone una innovación en la

(14) López Pellicer, en Los proyectos de obras municipales, I.E.A.L., 1975, páginas 122 y sigs., hace una referencia bastante completa a los supuestos de proyectos de obras municipales que requieren informe de organismos distintos de la Entidad municipal que los promueve: 1) los mercados minoristas subvencionados por la $\mathrm{Co}$ misaría General de Abastecimientos y Transportes han de someterse a la consideración del Ministro de Comercio; 2) los proyectos de mataderos frigoríficos precisan informe previo favorable del Ministerio de Agricultura (Decreto de 18 de agosto de 1972); 3) los proyectos de obras de centros de E.G.B. deberán ser sometidos a informe, se entiende, del Ministerio de Educación y Ciencia; 4) la construcción, transformación, etc., de instalaciones deportivas cuando se realicen con auxilio de la Delegación de Deportes (hoy Dirección General de Educación Física y Deportes), se someterán a informe de este organismo; 5) idem por lo que se refiere a piscinas públicas municipales que requieran informe sanitario previo y preceptivo de la Dirección General de Sanidad y Junta Consultiva de Espectáculos; 6) los proyectos de obras de viviendas de protección oficial ejecutados por los Ayuntamientos, se someterán a calificación e informe del Instituto Nacional de la Vivienda; 7) las obras que supongan nuevos aprovechamientos en zonas y centros de interés turístico, se dará audiencia del proyecto a la Administración turística, y si su informe fuese desfavorable, el proyecto, previo dictamen de la Comisión Interministerial de Turismo, se resolverá por el Consejo de Ministros.

(15) Con posterioridad a la redacción del presente trabajo apareci6 la Ley 40/81, que sustituye al Real Decreto-ley 3/81, concretamente alterando el tema de la advertencia de ilegalidad. A fin de seguir la línea expositiva he preferido mantener el texto inicial, adicionando al final una parte dedicada a la normativa objeto de sustitución. 
actividad informante, tal y como ha quedado expuesto anteriormente, y que se justifica por la importancia del asunto para el que se requiere un quórum que lógicamente demanda un asesoramiento especial.

Cabe, no obstante, considerar este supuesto dentro de los dictámenes en asuntos de importancia o calificados de interés, a los que se refieren los artículos 286, 1, del Reglamento de Organización, Funcionamiento y Régimen jurídico, y 143, 3, del Reglamento de Funcionarios, si bien en estos casos la emisión del informe quedaba a juicio del Secretario y ahora se estima preceptivo.

En cuanto al segundo supuesto, trae su causa también del citado artículo 143, 3, del Reglamento de Funcionarios, bastando que el acuerdo de la Corporación solicitando el informe se adopte por un tercio de sus miembros y no por número superior, como se deducía de la redacción anterior del citado precepto.

La primera cuestión que surge, a la vista de esta nueva regulación de los informes a emitir por Secretarios e Interventores, es si dicha actividad ha quedado reducida a los dos supuestos examinados o si, por el contrario, subsisten otras modalidades de informes, concretamente y por la trascendencia que tiene, la denominada advertencia de ilegalidad.

La respuesta viene, evidentemente, vinculada al alcance derogatorio del Real Decreto-ley 3/81.

Voy a intentar acercarme a este tema analizando dicho alcance, tanto desde los antecedentes de hecho de la citada norma como de la regulación que en su parte dispositiva se lleva a cabo de la figura de la suspensión de acuerdos.

Es frecuente y casi habitual el empleo por el legislador de las denominadas disposiciones derogatorias genéricas, que cómodamente para él se resuelven con la consabida cláusula de "quedan derogadas cuantas disposiciones de igual o inferior rango se opongan a la presente».

Con ello se incumple una norma legal y se encomienda a quien ha de cumplir la norma o al meramente interesado una función interpretativa que, si ciertamente constituye una de las tareas más apasionantes de la aplicación práctica del Derecho, no deja de entrañar unas ciertas dosis de riesgo e incertidumbre jurídicas, que en muchos casos no encuentran otra solución que la procesal ante los Tribunales de Justicia. 
Incumplimiento de una norma legal, digo, porque de todos es conocido - aunque parece que el legislador lo olvida a menudoel mandato contenido en el artículo 129, 3, de la Ley de Procedimiento Administrativo, a cuyo tenor, dentro del procedimiento para la elaboración de disposiciones generales, no podrá formularse ninguna propuesta de nueva disposición sin que en ésta se consignen expresamente las anteriores que han de quedar total o parcialmente derogadas, previsión que, como recuerda GonZález Pérez (16), tiende a «evitar en lo posible la anarquía normativa que caracteriza a nuestra Administración».

El Real Decreto-ley que me ocupa omite la tabla de derogaciones, pero conviene tener en cuenta (sin dejar de reconocer su valor oficioso) que el borrador o proyecto de dicha disposición que circuló, y del que tuvimos conocimiento, sí contenía una enumeración de normas derogadas, entre ellas el artículo 413 de la Ley de Régimen local, que no se publicó en el Boletín Oficial del Estado, en el que vio la luz el Decreto-ley.

Esta circunstancia obliga a un razonamiento interpretativo en busca de una solución válida.

La doctrina adinistrativista ha considerado, en general, a los actos preparatorios de las disposiciones legales o antecedentes legislativos, aun con anterioridad a la admisión que se lleva a cabo en el artículo 3 del Código Civil (reformado en 31 de mayo de 1974), como normas de interpretación a las que a veces habrá que acudir (17), estimando como tales, entre otros, los preámbulos, documentos previos de las Comisiones, las circunstancias de hecho que hayan rodeado a la promulgación, los precedentes que haya habido, etc. (18).

(16) Comentarios a la Ley de Procedimiento administrativo, Madrid, ed. Civitas, 1977, pág. 863.

Su frecuente omisión, sin embargo, calificada con evidente benignidad por el Tribunal Supremo. Vid. sentencias de 22 de noviembre de 1965 y 28 de septiembre de 1973: «... en lo que se refiere a la inobservancia de la aportación de la tabla de vigencias, es doctrina de esta Sala la de que tal falta no puede tener entidad con relieve suficiente para entender que el sentido teleológico del dato señalado produzca siempre... una indefensión para el administrado».

(17) Vid. García-Trevijano: Tratado de Derecho administrativo, tomo I, Madrid, ed. Revista de Derecho Privado, 1968, pág. 354.

(18) Vid. SAINZ MORENo: Conceptos jurídicos, interpretación y discrecionalidad administrativa, Madrid, ed. Civitas, 1976, págs. 150 y sigs., donde se abunda en la opinión expuesta y se mencionan, además, como antecedentes legislativos el expediente administrativo de elaboración del anteproyecto (art. 129 de la L.P.A.).

Puede consultarse también, en este aspecto, DE LA VEGA BENAYAS: Teoría, aplicación y eficacia de las normas del Código Civil, Madrid, ed. Civitas, 1976, págs. 122 y sigs., y DíEz PICAzo: Experiencias juridicas y teorias del Derecho, Barcelona, ed. Ariel, 1973 y 1975, pág. 249. 
Pues bien, volviendo al tema que me ocupa, cabe establecer las siguientes premisas:

1) Existencia de un antecedente de hecho (borrador o proyecto elaborado por la Administración) del Real Decreto-ley 3/81, que deroga expresamente unos artículos de la Ley de Régimen local y del Reglamento de Organización, Funcionamiento y Régimen jurídico.

2) Dicha derogación expresa no se publica en el Boletín Oficial del Estado con la disposición.

Esto supuesto pueden aventurarse dos soluciones:

A) Que la omisión de la cláusula derogatoria significa un abandono de la misma por el legislador.

B) Irrelevancia de tal omisión por las razones que a continuación se exponen, adelantando que es ésta la opinión de la que participo.

En el presente caso, se mantiene una absoluta identidad entre la exposición de motivos y el texto dispositivo publicado en el $\mathrm{Bo}$ letín Oficial del Estado, por un lado, y el del borrador o proyecto, y si este último determinó unas derogaciones puntuales y concretas, éstas forzosamente han de mantenerse en el texto legal invariado, que vio su luz en la Gaceta de Madrid, ya que la fuerza derogatoria no deriva tanto del empleo de una u otra forma, como del propio contenido de la nueva norma.

Conclusión: que, a mi juicio, el Real Decreto-ley 3/81 ha derogado los artículos 413, 2, 3 y 4, de la Ley de Régimen local, y 143, 1, del Reglamento de Funcionarios, que regulaban la advertencia de ilegalidad.

Pero aún hay más a favor de la afirmación antedicha.

La Disposición derogatoria del Real Decreto-ley 3/81, que se publicó en el Boletín Oficial del Estado, dice así:

«Quedan derogadas cuantas disposiciones de igual o inferior rango se opongan a lo dispuesto en el presente Real Decreto-ley».

¿A qué conclusión se puede llegar por la vía de la técnica de oposición inter normas?

El Real Decreto-ley tan citado incide en una materia cual es la 
actividad informante de ciertos funcionarios, en cuanto que dicha actividad se inscribe y conecta con el régimen jurídico de la adopción de acuerdos. Conviene no olvidar esto porque la figura de la advertencia de ilegalidad —objeto central de esta parte de mi trabajo- si bien supone una modalidad de informe, es algo más que esto, ya que entraña y determina todo un cualificado sistema de control de los acuerdos de la Administración local por parte de determinados órganos de la Administración del Estado. Y baste para comprobarlo la simple lectura del artículo 413 de la Ley de Régimen local.

El artículo 8 del Real Decreto-ley $3 / 81$ regula la facultad de suspensión de acuerdos de las Corporaciones locales por parte de la Administración del Estado (o, en su caso, por las Entidades Territoriales Autónomas), en los que concurran las circunstancias de afectar directamente a materias del Estado (o de las citadas Entidades) y que constituyan infracción de las Leyes, circunstancias que, como ha precisado posteriormente el artículo 5 del Real Decreto-ley 1282/81, de 5 de junio, han de concurrir simultáneamente para que pueda entrar en juego la citada suspensión (19), especificándose la forma en que se han de comunicar los acuerdos, el ejercicio de la facultad suspensoria, la posibilidad de solicitud de ampliación de datos y antecedentes referentes a los actos y acuerdos adoptados y la forma y tiempo en que han de ser suministrados. Pues bien, en ningún lugar, tanto del Real Decreto-ley 3/81, como en el Real Decreto de 5 de junio, se menciona la advertencia de ilegalidad referida al acto o acuerdos, lo que significa lisa y llanamente su eliminación en la normativa vigente.

(19) La sentencia del Tribunal Constitucional de 2 de febrero de 1981 declara que el principio de autonomía es compatible con el control de legalidad sobre el ejercicio de las competencias, si bien entiende que no se ajusta a tal principio la previsión de controles genéricos e indeterminados que sitúen a las Entidades locales en una posición de subordinación o dependencia casi jerárquica de la Administración del Estado $u$ otras Entidades territoriales, y que, en todo caso, los controles puntuales habrán de referirse a supuestos en que el ejercicio de las competencias de la Entidad local incidan en intereses generales concurrentes con los propios de la Entidad, sean del Municipio, la Provincia, la Comunidad Autónoma o el Estado.

En este aspecto, es fundamental la consulta de la reciente obra de Parejo Alfonso: Garantía institucional y autonomias locales, I.E.A.L., Madrid, 1981, págs. 132 y sigs. 


\section{TRATAMIENTO JURIDICO DE LOS INFORMES EN LA NUEVA NORMATIVA}

Los informes regulados por el Real Decreto-ley 3/81 se configuran como necesarios (art. 4) o preceptivos (art. 4 del Real Decreto $1282 / 81$ ). Esto quiere decir que su emisión es indispensable para la producción válida del acto o acuerdo que lo requiere (20). Por el contrario, su omisión produce un vicio de procedimiento que determina la invalidez de las actuaciones posteriores sin posibilidad de convalidación, puesto que así lo preceptúa el artículo 53, apartado 5, de la Ley de Procedimiento Administrativo, y ello es lógico, ya que, como destacan GaRCía de ENTERRÍA y FERnÁNDEZ RodRíGUeZ (21), si la finalidad de los informes no es otra que ilustrar al órgano que ha de adoptar una resolución, carece absolutamente de sentido la producción del informe con posterioridad a la decisión.

Las formalidades de estos informes contienen unas particularidades de evidente interés y trascendencia sobre las que conviene detenerse.

A) Informes en asuntos que requieran quórum especial.

Estos informes han de emitirse por escrito y con anterioridad a la iniciación de la sesión en que hubiera de ser adoptado el correspondiente acuerdo (art. 4, 1, RD).

Su contenido, de conformidad con el citado artículo 4, 2, deberá referirse a la legislación aplicable en cada caso y la adecuación de los acuerdos a la misma.

B) Informes ordenados por el Presidente no solicitados por los miembros de la Corporación.

Este tipo de informes participa de los mismos requisitos de forma y contenido que los anteriormente examinados.

Sin embargo, revisten ciertas peculiaridades en cuanto al tiempo para su emisión.

El Real Decreto 1282/81 dispone, en el ya citado artículo 4, que

(20) Vid. GonzÁlez Pérez: Comentarios a la Ley de Procedimiento administrativo, cit., pág. 498.

(21) Curso de Derecho administrativo, tomo I, Madrid, ed. Civitas, 1974, pág. 463. 
el requerimiento o petición de informe deberá efectuarse con una antelación mínima de ocho días a la celebración de la sesión en la que habrá de debatirse el tema y, en su caso, adoptarse el acuerdo que proceda.

Evidentemente, esta regulación de un informe solicitado a un funcionario trata de garantizar tanto la seguridad profesional del propio funcionario, evitando requerimientos sorpresivos tan frecuentes en la práctica, como el acierto en la opinión fundada, acierto que, sin duda, se produce cuando se dispone de un tiempo prudencial suficiente y que, al fin y a la postre, a quien beneficia es al propio órgano decisor.

La disposición que se examina ha querido otorgar a este requisito temporal una cierta solemnidad, hasta el punto que su incumplimiento impide a la Corporación la adopción de acuerdo alguno sobre el que versase el informe. Imposibilidad legal, pues, que determinaría, aun en el caso de que la Corporación, pese a la prohibición legal, se pronunciase sobre el tema, la invalidez del acuerdo.

\section{CODA OBLIGADA: DEL LABERINTO LEGISLATIVO AL GALIMATIAS LOGICO}

El presente trabajo se elaboró durante el verano de 1981. Pretendía, a falta de otros valores, exponer una actividad administrativa de los funcionarios enlazando con una regulación nueva y de indudable interés. Intentaba ser práctico y, sobre todo, oportuno. La experiencia, de la que no terminamos de aprender, enseña que en materia de legislación, referida a la Administración local sobre todo, no hay actualmente norma que «cien días dure» y que toda impaciencia tiene su purgatorio.

Si al principio de estas líneas me lamentaba, no haciendo otra cosa que subrayar destacadas opiniones doctrinales, de la inestabilidad normativa a que se encuentra sometido el Régimen local, buen ejemplo para el lamento (mal ejemplo) se nos ha brindado con las disposiciones recientes de las que me he ocupado.

Veamos. Pasadas las vacaciones estivales, en las que las máquinas 
legislativa y administrativa quedan paralizadas, con la reanudación del curso oficial comienzan a hacer su aparición en el Boletín Oficial del Estado una serie de normas que obligan a replantearme lo expuesto en la última parte de este trabajo, concretamente lo referente a la regulación que de la denominada advertencia de ilegalidad llevaba a cabo el Real Decreto-ley 3/81.

El día 12 de noviembre de 1981, se publica en la Gaceta de Madrid la Ley $40 / 81$, de 28 de octubre, por la que se aprueban determinadas medidas sobre régimen jurídico de las Corporaciones locales. Esta Ley, cuya exposición de motivos se omitió en el Boletín, por lo que el lector de a pie queda sin conocer el porqué de su existir a los escasos meses de la entrada en vigor del Real Decretoley $3 / 81$, incide, por lo que al objeto de este trabajo se refiere, en los mismos temas de los que me he ocupado más arriba.

En efecto, el artículo 4 regula los informes obligatorios del Secretario e Interventor, en su caso, de la misma forma que el Real Decreto-ley.

No así el otro precepto del cual me ocupé, el artículo 8, en una y otra norma, y del cual extraía yo derivaciones a favor de la desaparición de la llamada advertencia de ilegalidad a que venían obligados, según la Ley de Régimen local, los Secretarios e Interventores.

Las variaciones estriban en lo siguiente: La Administración del Estado podrá impugnar ante la Jurisdicción Contencioso-administrativa (impugnación que determina su suspensión) los actos y acuerdos de las Corporaciones locales que constituyan infracción de las Leyes y, además, que afecten directamente a materias de la competencia del Estado.

Los dos supuestos, que se contenían en el Real Decreto-ley especificados en párrafos numerados y aparte uno de otro, han quedado unificados en la Ley.

Hasta aquí nada más tendríamos que adicionar a lo ya expuesto. Sólo añadir, por lo que más adelante se dirá, que realmente es una no desdeñable ventaja la del redactor de ambas normas, que por el juego de las Leyes sustitutorias, a cortísimo plazo, dispone de un medio eficaz de subsanar errores o simplemente perfeccionar un texto que ya había alcanzado vigor. Las situaciones creadas durante el lapso de vigencia de la Ley sustituida es, al parecer, lo de menos. 
El ciclo normativo que voy exponiendo, y que el paciente lector habrá podido comprobar que se produce dentro de los cauces de un tradicional género literario, es decir, "por entregas», se completa, por ahora, y por supuesto fuera de plazo, con el Real Decreto 3183/ 1981, de 29 de diciembre ( $B O E$ del 31), que deroga el punto cuatro del artículo 413 de la Ley de Régimen local, es decir, el referente a la remisión al Gobernador civil de la certificación de los acuerdos adoptados sobre los que se hubiese formulado advertencia de ilegalidad, dejando subsistentes los anteriores apartados 1,2 y 3 , que obligan, so pena de incurrir en responsabilidad, a formular la tan repetida advertencia de manifiesta infracción legal.

Bien. Ante esta declaración de lege data parece que no cabría ya otra posición que poner punto final a estas líneas aceptando la solución legal sin más.

No me resisto, sin embargo, a añadir, por mi parte, una coletilla a este puzzle legislativo.

La Ley 40/81, conforme a la tabla de vigencias, de 29 de diciembre, ha derogado desde el 12 de noviembre al Real Decreto-ley 3/81. Consideremos, pues, lo dicho anteriormente respecto de esta norma para las situaciones creadas durante su efímera vigencia, sin desdeñar su relativo valor como antecedente para posibles cuestiones homogéneas que puedan producirse.

Asimismo insistir en la omisión reiterada en la Ley 40/81 de la tabla de vigencias, que dado el encargo que en la misma se hace al Gobierno es de suponer que no acompañó al proyecto o anteproyecto que redactó la Administración, incumpliendo una vez más las normas previstas en el artículo 129, 3, de la Ley Procesal Administrativa.

Bien es sabido que esta omisión, en cuanto a la preparación de proyectos y anteproyectos de Ley se refiere (cual es el caso que me ocupa), no afecta a la validez de la Ley que se dicte, la cual, como observan García de ENTERRÍA y Fernández Rodríguez (22), aun habiendo infringido el procedimiento que debe observarse, tendrá la misma fuerza que la Ley de Procedimiento Administrativo. Pero no es menos cierto que independientemente de esta consecuencia, la

(22) Curso de Derecho administrativo, tomo I, 1." edición, Civitas, pág. 120. 
84

seguridad jurídica que debe presidir todo cambio legislativo se ve seriamente quebrada, contribuyendo a confusiones y dando la imagen inevitable de una actuación incompleta, defectuosa y precipitada por parte de los encargados de la preparación de los textos legales (23).

(23) Al fenómeno del incumplimiento de las normas para elaborar disposiciones generales ha dedicado recientemente un interesante comentario BERMEJo VERA, en Revista Española de Derecho Administrativo, núm. 30, Civitas, pág. 539, bajo el título «La relativización del procedimiento para elaborar disposiciones de carácter general». 